\title{
Mantodea oasis of Palaearctic region: biogeographical analysis of Mantodea in Egypt
}

\author{
M. Okely, M. Nasser, R. Enan, S. GadAllah and S. AlAshaal
}

\begin{abstract}
Background: Egypt forms a home for the highest number of recorded Mantodea species of the Palaearctic Region. The status and ecology of such diversity are far from being completely understood.

Main body: Through this study, the similarity of Mantodea species composition among Egyptian ecological zones has been examined by using the Sørensen-Dice coefficient, beside the calculation of species richness for each zone. Also, maximum entropy (Maxent) modeling was used to estimate the potential distribution of Mantodea species throughout the country. Three topographical and 19 bioclimatic variables have been used to estimate the current status of all Mantodea species in Egypt. The collected materials of adult mantis have been used to analyze the seasonality of 14 Egyptian common genera. Our results indicated that there was a high faunal similarity between the Western and Eastern deserts, the coastal strip, and the lower Nile valley. The lowest similarity was between Gebel Elba and all other zones. The analysis of habitat suitability of Mantodea in Egypt was fragmentary and focused on different distinct ecological zones. Altitude was the most effective ecological factor that affected Mantodea distribution as a group. Analysis of seasonality data of the common genera of Mantodea indicated that all are found in summer except for Miomantis, Severinia, and Sinaiella.
\end{abstract}

Conclusion: Our results can be used as a basis for future studies of the ecology of certain species and conservation of this interesting group in Egypt.

Keywords: Maxent, Climatic niches, Sørensen-Dice coefficient, Ecological zones, Egypt

\section{Background}

Mantodea is a group of mostly large predatory insects, distributed in tropical and subtropical habitats of the world (Ehrmann 2001; Otte and Spearman 2005). It includes approximately 2500 species (Ehrmann 2002; Schwarz and Roy 2019; Greyvenstein et al. 2020). Mantis is exclusively carnivorous feeding mainly on other arthropods as well as small vertebrates (Prete et al. 2002). Mantis has a very important ecological role in the suppression of herbivorous insect populations including some agriculture pests with very few species, with biological control impact (Symondson et al. 2002).

\footnotetext{
* Correspondence: sara_alashaal@sci.asu.edu.eg

Entomology Department, Faculty of Science, Ain Shams University, Cairo, Egypt
}

Although it is a large desert country with sand dunes form 96\% of its land (Hoath 1993), Egypt constitutes the highest biodiversity of order Mantodea in the Palaearctic Region (Mohammad et al. 2011; Enan et al. 2017). The total number of Mantodea species in Egypt is 60 species under 21 genera and 4 families (Empusidae, Eremiphilimantis to cross the Sahara Desert. Also, it separates the desecies such as Eremiaphila in the country (Battiston et al. 2010). Although the diversity of Mantodea in Egypt is high, the number of individuals previously 
collected was low (Sawaby et al. 2010). However, there were several studies concerning mantis taxonomy in Egypt; those discussing their distribution and ecological parameters governing such distribution are scared (Sawaby et al. 2010).

Nowadays, ecology relies on data science through most of its research areas (Hirzel et al. 2002; Moulin 2020). Distribution modeling has been considered as an important technique to formalize the link between the species and their geographical surroundings, in particular, to quantify the parameters which govern their presence (Peterson et al. 2007; Abutaleb et al. 2019). In recent years, such an approach received increased attention to assess the geographical distribution of species and was applied to the fields of ecology and conservation biology (Ganeshaiah et al. 2003; Levine et al. 2004; Ma'moun et al. 2017; Hosni et al. 2020).

Analysis of biogeographical data of predator or parasite species helps in studying their distribution in different regions and provides an essential tool for conservation planning and biological control strategies (Brown and Lomolino 1998; Ladle and Whittaker 2011; Nasser et al. 2015, 2019a, b; Keerthi et al. 2020). There are several insect groups which face neglection in their ecological study in Egypt (Abutaleb et al. 2019; Adly et al. 2019). Accordingly, the present study was conducted and focused on calculating the zoogeographical affinities of mantises and modeling the distribution pattern of Mantodea as a group in different Egyptian ecological zones, estimating species richness, analyzing bioclimatic, and geographical factors that contribute to such distribution using GIS and for better understanding the ecology of these charismatic predators.

\section{Materials and methods}

\section{Study area}

The study was conducted in Egypt (31 $12^{\prime} 20.7108^{\prime \prime} \mathrm{N}$; $29^{\circ} 55^{\prime} 28.2936^{\prime \prime} \mathrm{E}$ ), which located in the northeastern corner of Africa, covering an area of $1,001,449 \mathrm{~km}^{2}$. Egypt is divided into eight ecological regions: coastal strip, Lower Nile Valley (Nile Delta), Upper Nile Valley, Fayoum Basin, Eastern Desert, Western Desert, Sinai, and Gebel Elba (El-Hawagry and Gilbert 2014).

\section{Mantodea data and sampling}

The existing data of Mantodea species were obtained from the biodiversity database, including Project Noah (http://www.projectnoah.org), the Global Biodiversity Information Facility (http://www.gbif.org/), museum collections of the State Museum of Natural History Karlsruhe, Ain Shams University, Cairo University, Egyptian Society of Entomology, Al-Azhar University, and the Ministry of Agriculture, from the literatures (Giglio-Tos 1921; Marshall 1975; Ehrmann 1996; El-Moursy et al.
2001; Mohammad et al. 2011), and specimens collected during a large series of field trips in different ecological zones (Alexandria, Aswan, Faiyum, Hurghada, Gabal Alba Protected Area, North Coast, Sant Katherine, and Siwa) by the second author (2008 to 2010) and first author at 2017 (El Qoseir, Quena, Ras Mohammed National Park, Sharm El-Sheikh, Wadi Rayan Protected Area). Visual inspection of vegetation and swiping net were used as the main method to collect Mantodea samples during the fieldwork (Supplementary 1).

\section{Ecological zones affinity analysis}

The number of observations and species in the database was tabulated separately for each ecological zone. The number of observations per species was calculated to estimate the intensity of collection by an ecological zone that indicates the species richness in each of them. In addition, to study the similarity of species composition among such ecological zones, we used the Sørensen-Dice coefficient or Sørensen similarity index

$\left[\mathrm{S}_{\mathrm{s}}=2 \mathrm{a} /(\mathrm{b}+\mathrm{c})\right.$ where $a=$ number of species in both zones, $b=$ number of species in the $1^{\text {st }}$ zone, and $c=$ number of species in the 2 nd zone] which ranges from 0 to 1 (Dice 1945; Sørensen 1948). The dendrogram was constructed according to the unweighted pair-group mean arithmetic method (UPGMA) using the PAST (Paleontological Statistics Version 3; Hammer et al. 2001) computerized software.

\section{Ecological modeling of Mantodea}

The present climatic data were downloaded from the WorldClim database with a spatial resolution of $2.5 \mathrm{~min}$ (http://www.worldclim.org) while altitude, aspect, and slope were calculated using ArcGIS 10.3. All these bioclimatic layers were clipped to match the dimension of Egypt by using ArcGIS software V. 10.3. In this study, 19 climatic and 3 topographical variables were used to estimate the current status of Mantodea as a group (Table 1). No elimination of any bioclimatic factors has made as we apply them to the heterogenous group as Mantodea.

Maximum entropy model (MaxEnt) is one of the very important tools that is applied for conducting species distribution modeling due to its ability to fit in low sample size and easy to produce an accurate model (Phillips et al. 2006; Peterson et al. 2007; Elith and Leathwick 2009). When a low number of sample localities are available, MaxEnt can predict the species distribution modeling more efficiently than other ecological niche models. It can produce a habitat suitability map, and the importance of individual environmental variables can be evaluated using jackknife test (Anderson et al. 2006; Hernandez et al. 2008). Moreover, Maxent facilitates the 
Table 1 Environmental and topographical variables used in Maxent to predict the current habitat suitability distribution of Mantodea species

\begin{tabular}{|c|c|}
\hline Variable & Description \\
\hline Bio 1 & Annual mean temperature \\
\hline Bio 2 & $\begin{array}{l}\text { Mean diurnal range (mean of monthly max temp - min } \\
\text { temp) }\end{array}$ \\
\hline Bio 3 & Isothermality (bio2/bio7) × 100 \\
\hline Bio 4 & Temperature seasonality (standard deviation $\times 100$ ) \\
\hline Bio 5 & Max temperature of the warmest month \\
\hline Bio 6 & Min temperature of the coldest month \\
\hline Bio 7 & Temperature annual range \\
\hline Bio 8 & Mean temperature of the wettest quarter \\
\hline Bio 9 & Mean temperature of the driest quarter \\
\hline Bio 10 & Mean temperature of the warmest quarter \\
\hline Bio 11 & Mean temperature of the coldest quarter \\
\hline Bio 12 & Annual precipitation \\
\hline Bio 13 & Precipitation of the wettest month \\
\hline Bio 14 & Precipitation of the driest month \\
\hline Bio 15 & Precipitation seasonality (coefficient of variation) \\
\hline Bio 16 & Precipitation of the wettest quarter \\
\hline Bio 17 & Precipitation of the driest quarter \\
\hline Bio 18 & Precipitation of the warmest quarter \\
\hline Bio 19 & Precipitation of the coldest quarter \\
\hline Altitude & Altitude in degrees \\
\hline Aspect & Aspect ratio \\
\hline Slope & Slope \\
\hline
\end{tabular}

replication run that allows cross-validation and tests the model performance by repeating subsampling (Adhikari et al. 2012).

To produce a model for the range of the species, this model takes input as a set of environmental layers and a set of occurrence records. The occurrence records were randomly partitioned for model evaluation into two subsamples: $75 \%$ of the records were used for training and $25 \%$ of the records were used for testing the model accuracy. Twenty replicate runs were assigned to generate the average, maximum, minimum, and median of the distribution range of Mantodea species. The contributions of all variables were determined by producing the jackknife approach in Maxent software (Pearson et al. 2007).

\section{Model evaluation}

The performance efficiency was determined by several statistical tests. The area under curve (AUC) values of receiver operating characteristic (ROC) curves (Phillips et al. 2006; Peterson et al. 2008). In general, AUC is between 0.5 and 1 where an AUC of 0.5 indicates that the model did not perform better than random, values between 0.5 and 0.7 indicate poor prediction ability, values of $0.7-0.9$ indicate moderate prediction, and values above 0.9 indicate strong prediction (Swets 1988). Also, the model predictions were tested using the partial ROC (pROC) statistics to test model robustness (Peterson et al. 2008; Okely et al. 2020). Finally, the True Skilled Statistics (TSS) was made to assess the accuracy of the models from the logistic values of background prediction. The values of the test range from -1 to 1 and if it is close to negative or zero imply that the distribution is not much better than random; on the other hand, the values close to 1 indicate an intimate relationship between the model prediction and actual distribution (Hosni et al. 2020).

\section{Seasonality analysis}

The analysis of seasonality data of the common 14 genera of Mantodea was based on the data of collected samples and several previous literatures (Giglio-Tos 1921; Marshall 1975; Ehrmann 1996; El-Moursy et al. 2001; Battiston et al. 2010; Mohammad et al. 2011).

\section{Results and discussion}

The analysis of Mantodea records in the Egyptian fauna showed that Blepharopsis mendica has the highest number of records with 90 occurrence points. On the other hand, 23 species Empusa fasciata, Dilatempusa aegyptiaca, Eremiaphila anubis, Eremiaphila berndstiewi, Eremiaphila brevipennis, Eremiaphila cairina, Eremiaphila hedenborgii, Eremiaphila lefebvrii, Eremiaphila luxori, Eremiaphila nilotica, Eremiaphila rohlfsi, Eremiaphila rufipennis, Elaea gestroi gestroi, Elaea marchali, Elaea solimani, Ischnomantis perfida, Microthespis dmitriewi, Oxyothespis dumonti, Sinaiella nebulosa, Sinaiella sabulosa, Heterochaeta pantherina, Paroxyophthalmus

Table 2 Mantodea distribution by the ecological zone in Egypt. Number of observations (obs), species, and ratio of observations to species

\begin{tabular}{llll}
\hline Ecological zone & Obs & Species & Obs/species \\
\hline Coastal Strip & 33 & 17 & 1.9 \\
Lower Nile Valley (including the Delta) & 184 & 23 & 8 \\
Upper Nile Valley & 20 & 12 & 1.7 \\
Fayoum Basin & 18 & 7 & 2.6 \\
Eastern Desert & 48 & 22 & 2.2 \\
Western Desert & 58 & 25 & 2.3 \\
Sinai & 86 & 19 & 4.5 \\
Gebel Elba & 3 & 2 & 1.5 \\
Total & 450 & 127 & 24.7 \\
\hline
\end{tabular}


Western Desert (25)

Lower Nile Valley (23)

Eastern Desert (22)

Sinai (19)

Coastal Strip (17)

Upper Nile Valley (12)

Fayoum Basin (7)

Gebel Elba (2)

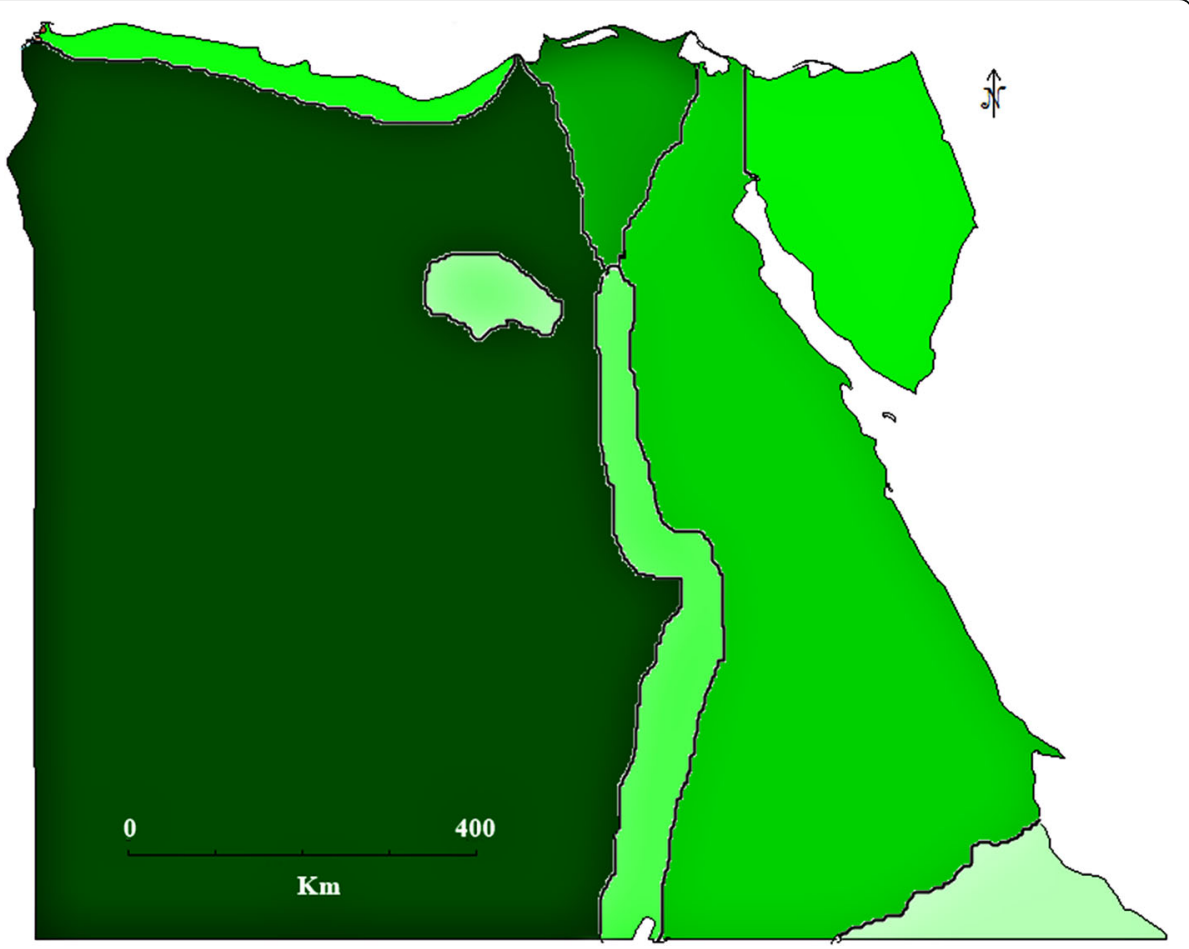

Fig. 1 Map of Egypt showing the eight ecological zones and the total number of Mantodea species collected from each zone

collaris, and Tarachodes (Chiropacha) gilvus were recorded only once.

Mantodea species occur in the eight ecological zones of Egypt (Table 2, Fig. 1). Four ecological zones (Lower Nile Valley and Delta, Sinai, Western Desert, and Eastern Desert) accounted $83.6 \%$ of the records in the database, while the other four zones (Coastal Strip, Upper Nile Valley, Fayoum Basin, and Gebel Elba) accounted $16.4 \%$ of the records. The Western Desert has by far the highest number of species (25 species, 19.7\%), and Gebel Elba has the lowest number (2 species, 1.6\%) (data from Gebel Elba is not accurate as visiting this zone is very difficult and maybe not allowed for security reasons).
The observations per species ratios strongly varied across the different ecological zones (Table 2). The ratio was very high in Lower Nile Valley (8) and Sinai (4.5) indicating that these two ecological zones have been explored more intensively than the other zones.

The Egyptian ecological zones vary in their compositional similarity to each other (Table 3 ). The highest similarity was between Coastal Strip and the lower Nile Valley, while the lowest similarity was between Gebel Elba and the Western Desert. Similarities were lower between Gebel Elba and any of the other zones. Also, the Eastern Desert and Western Desert have similarities to one another, forming one cluster (Fig.

Table 3 The similarity of mantis faunas in the Egyptian ecological zones. The number of species shared between each pair of zones is given in the upper half of the table, and the Sørensen-Dice coefficient between each pair of zones is given in the lower half of the table

\begin{tabular}{|c|c|c|c|c|c|c|c|c|}
\hline & Coastal strip & Lower Nile Valley & Upper Nile Valley & Fayoum Basin & Eastern Desert & Western Desert & Sinai & Gebel Elba \\
\hline Coastal strip & - & 10 & 5 & 6 & 6 & 11 & 8 & 1 \\
\hline Lower Nile Valley & 0.55 & - & 7 & 6 & 9 & 10 & 11 & 1 \\
\hline Upper Nile Valley & 0.34 & 0.4 & - & 4 & 3 & 7 & 4 & 1 \\
\hline Fayoum Basin & 0.5 & 0.4 & 0.42 & - & 4 & 6 & 5 & 1 \\
\hline Eastern Desert & 0.35 & 0.4 & 0.18 & 0.28 & - & 10 & 5 & 2 \\
\hline Western Desert & 0.52 & 0.41 & 0.38 & 0.38 & 0.42 & - & 5 & 1 \\
\hline Sinai & 0.44 & 0.52 & 0.25 & 0.38 & 0.3 & 0.27 & - & 1 \\
\hline Gebel Elba & 0.1 & 0.08 & 0.14 & 0.22 & 0.16 & 0.07 & 0.1 & - \\
\hline
\end{tabular}


2). The habitat suitability of Mantodea in Egypt was fragmentary and focused in different distinct ecological zones. Areas with a high probability of Mantodea were predicted in the Lower Nile Valley, Coastal Strip, Red Sea Coast, North-Eastern part of the country (Sinai), Luxor on Upper Nile valley, and South Sinai. There were also some predicted areas of Mantodea in the western part of the country including Siwa Oasis (Fig. 3).

The Western desert had the highest number of species, but the number of observations was low as compared to the Lower Nile Valley and Delta which had the highest number of observations. Because the number of observations and species tends to rise with collecting effort, the ecological zones with a low ratio (observation/species) would be the most places to find species that have not been discovered. The similarities between the eight ecological zones showed that Gabel Elba has the lowest similarities due to that it belongs to the Afrotropical Region. This result is compatible with the result of El-Hawagry and Gilbert (2014). The Eastern and Western Deserts have a high similarity to each other; this is due to that both form a part of the Sahara Desert.

The Maxent model for Mantodea as a group provided satisfactory results, with an AUC value of 0.887 for test and 0.954 for training which is higher than 0.5 of a random model. ENM for Mantodea species yielded predictions that gave an area under the curve (AUC) ratios above the null expectations in partial ROC analyses $(P<0.001)$, where the minimum, maximum, and mean pROC values are 1.4, 1.6, and 1.49, respectively. Also, the results of (TSS) show a high degree of confidently with a value of 0.872 .

Altitude showed a higher effect on the distribution of Mantodea relative to the other variables (Fig. 4). It had the top contribution of $36.2 \%$ to the model. Temperature-related variables had $49.4 \%$ contribution to the model of which the mean temperature of the coldest quarter (bio11) gave the highest influence on the model with $16.2 \%$ (Table 4). Precipitation-related variables had a relatively small influence on the model with only $10.7 \%$ contribution. Among these variables' precipitation of the wettest month (bio 13) gave the highest influence on the model with 3.7\% contribution. Slope and aspect had a small influence on the model with only $2.9 \%$ and $0.9 \%$, respectively. The only variable that had no effect on the model was precipitation of the driest month (bio 14) with zero contributions (Table 4).

Our modeling showed that the Western Desert had a low habitat suitability to Mantodea species (Fig. 4). Although this result is unexpected, this may be due to the domination of genus Eremiaphila (a desert mantis) in such harsh environment. The lowest number of collected samples of this genus from the region

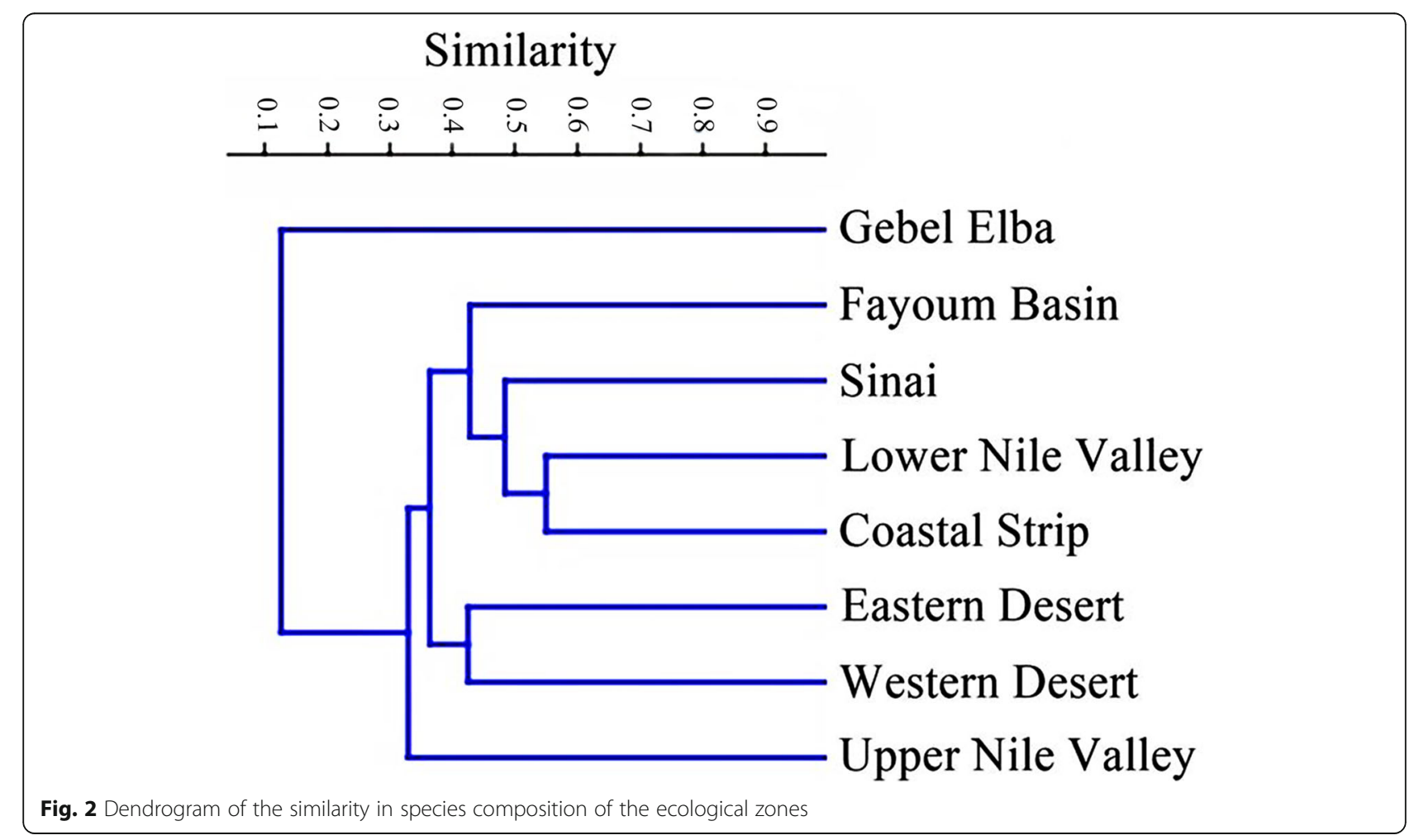




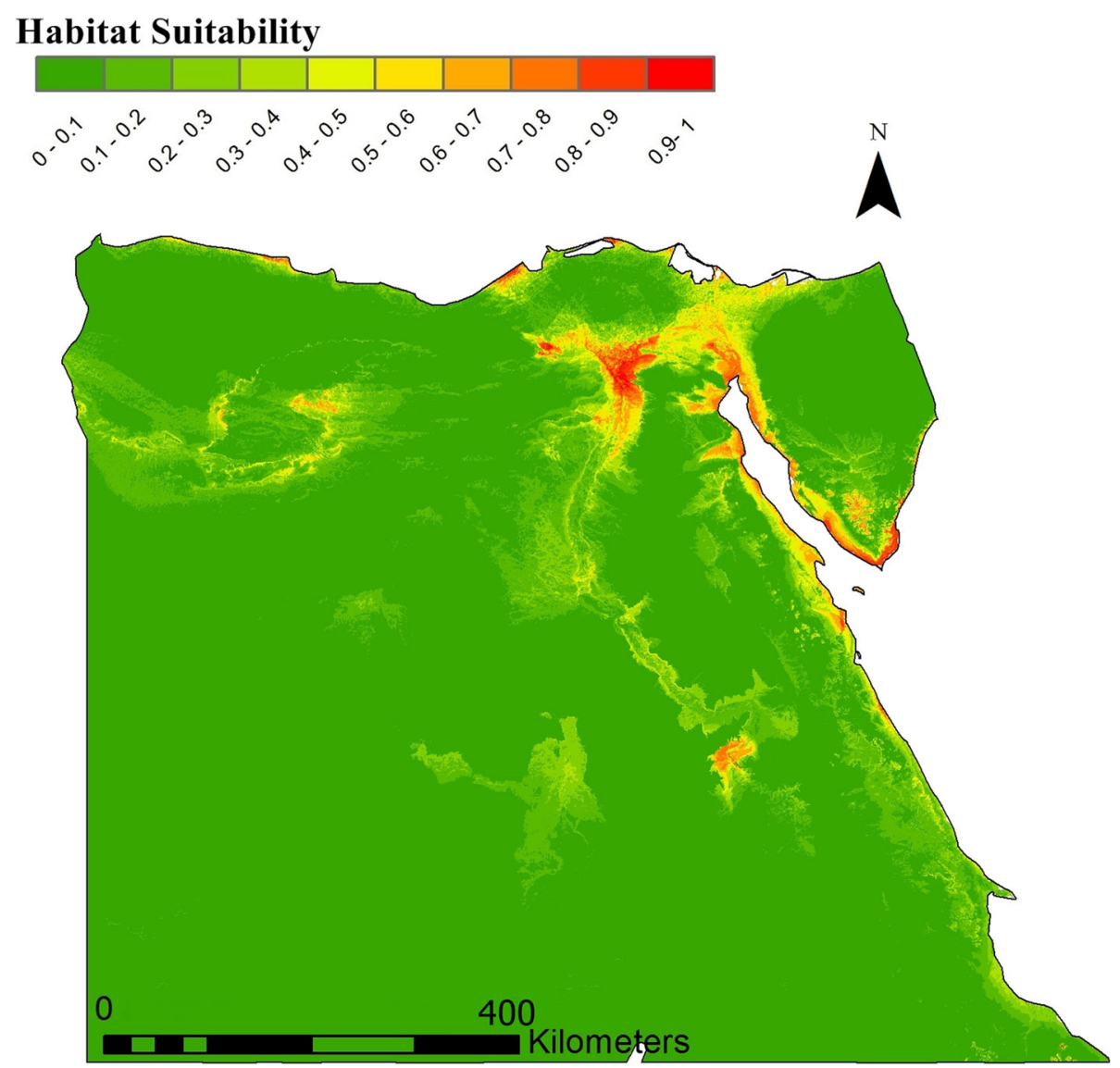

Fig. 3 Habitat suitability of Mantodea species in Egypt according to occurrence records

forms the main reason for such results. In general, the genus Eremiaphila faces a lack of representative samples in museums collection (Nasser 2010), and they are difficult to collect in the field as its species live in remote places of desert areas and mimic stones and sand (Preston-Mafham 1990). The results of our model (Fig. 4) are compatible with the ratio between observation/species (Table 2) which indicate that the Lower Nile Valley and Delta have a high habitat suitability with a high ratio. Also, coasts of the Mediterranean, Red Sea, and Sinai have a high suitability to Mantodea species. These areas receive the higher rainfall in the winter months (El-Hawagry 2002). This may explain the impact of precipitation of wettest month (bio 13) on the modeling of habitat suitability. Altitude forms the main factor that affects the distribution of Mantodea as a group and such an interesting upshot agrees with several previous publications concerning the group ecology (Shcherbakov and Savitsky 2015; Moulin et al. 2017).

The heterogeneity of ecological requirements of different species of mantis used in our model could form a limitation for the final results, but on the other hand, the final map gave us ideas about areas with high mantis concentration, the regions that need more surveillance efforts, an area that is very suitable for mantis as a potential biological control agent, and the part of mantis community that occupied conserved areas such as that found on in St. Catherine and NABQ-protected areas in Sinai. The final map gives an idea about the order-as a whole-not for a specific genus or species, especially the desert mantis that has somewhat completely different habitat than any other Mantodea group (Ranade et al. 2004).

Analysis of seasonality data of Mantodea genera (Fig. 5) indicated that mantis and Sphodromantis reach the adult stage in summer and overwinter as Ootheca, Miomantis present in the adult stage from spring to winter, Rivetina can be found as the adult stage from early summer to late autumn, Severinia seems to be present in the adult stage from winter to spring, Sinaiella can be found as the adult stage from early winter to late spring, Heterochaeta can be found in the adult stage during summer, Empusa and 


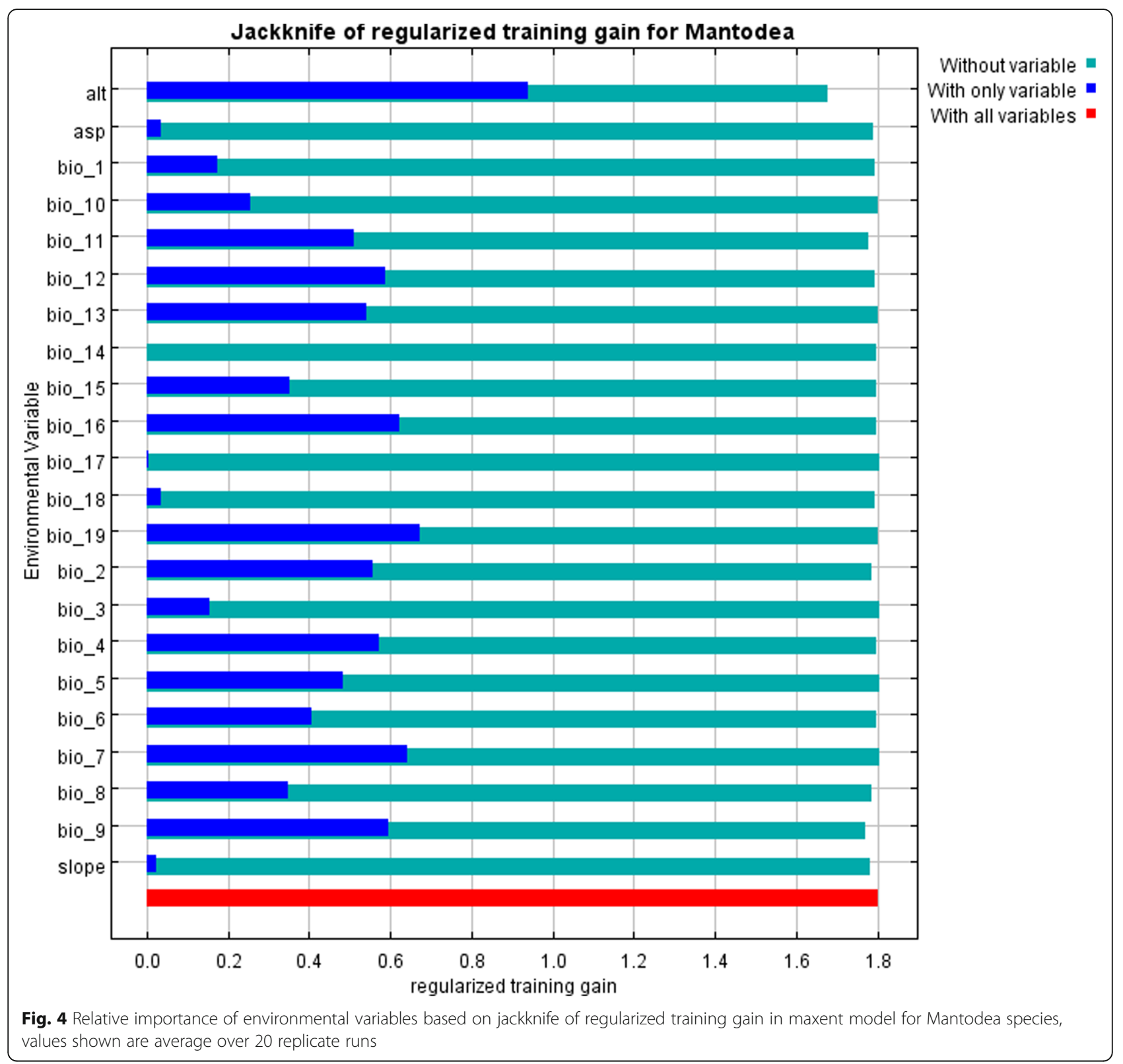

Hypsicorypha overwinter as nymphs and adults can be found in late spring, Iris seems to be found as the adult stage in late summer and eggs hatch in spring, Elaea can be found as the adult stage from spring to summer, Eremiaphila and Heteronutarsus can be found almost throughout the year, and finally, Blepharopsis overwinters as a nymph and the adult can be found in spring.

Most of the mantis species have only one generation a year (Hogue and Powell 1980). The seasonality analysis of the common 14 genera indicated that 11 of them reach the adult stage in spring and summer and 3 genera (Miomantis, Severinia, and Sinaiella) live as the adult stage in winter and spring. Most mantis species preferred warm weather, and the hatching of their eggs usually depends on temperature (Hurd et al. 1995). This may explain why the impact of the mean temperature of the coldest quarter (bio11) on the modeling of habitat suitability is high as the temperature of winter months will greatly affect the hatching of the eggs and development of the nymphal stage.

\section{Conclusion}

The present study represents the first attempt to study the biogeography of Mantodea as a group in different ecological zones in Egypt. The way is still so far from getting a complete understanding of mantis habitat in the country, and great efforts are needed in monitoring 
Table 4 The contribution percentage of the total 22 ecological and topographic layers in predicting the spatial distribution of Mantodea species in Egypt

\begin{tabular}{|c|c|c|}
\hline Variable & Description & Contribution $\%$ \\
\hline Bio 1 & Annual mean temperature & 2.8 \\
\hline Bio 2 & Mean diurnal range (mean of monthly (max temp - min temp) & 4.5 \\
\hline Bio 3 & Isothermality (bio2/bio7) × 100 & 1.1 \\
\hline Bio 4 & Temperature seasonality $($ standard deviation $\times 100$ ) & 1.4 \\
\hline Bio 5 & Max temperature of the warmest month & 5.9 \\
\hline Bio 6 & Min temperature of the coldest month & 0.7 \\
\hline Bio 7 & Temperature annual range & 7.8 \\
\hline Bio 8 & Mean temperature of the wettest quarter & 2.6 \\
\hline Bio 9 & Mean temperature of the driest quarter & 6 \\
\hline Bio 10 & Mean temperature of the warmest quarter & 0.4 \\
\hline Bio 11 & Mean temperature of the coldest quarter & 16.2 \\
\hline Bio 12 & Annual precipitation & 1.7 \\
\hline Bio 13 & Precipitation of the wettest month & 3.7 \\
\hline Bio 14 & Precipitation of the driest month & 0 \\
\hline Bio 15 & Precipitation seasonality (coefficient of variation) & 0.9 \\
\hline Bio 16 & Precipitation of the wettest quarter & 1.5 \\
\hline Bio 17 & Precipitation of the driest quarter & 0.3 \\
\hline Bio 18 & Precipitation of the warmest quarter & 0.4 \\
\hline Bio 19 & Precipitation of the coldest quarter & 2.2 \\
\hline Altitude & Altitude in degrees & 36.2 \\
\hline Aspect & Aspect ratio & 0.9 \\
\hline Slope & Slope & 2.9 \\
\hline
\end{tabular}

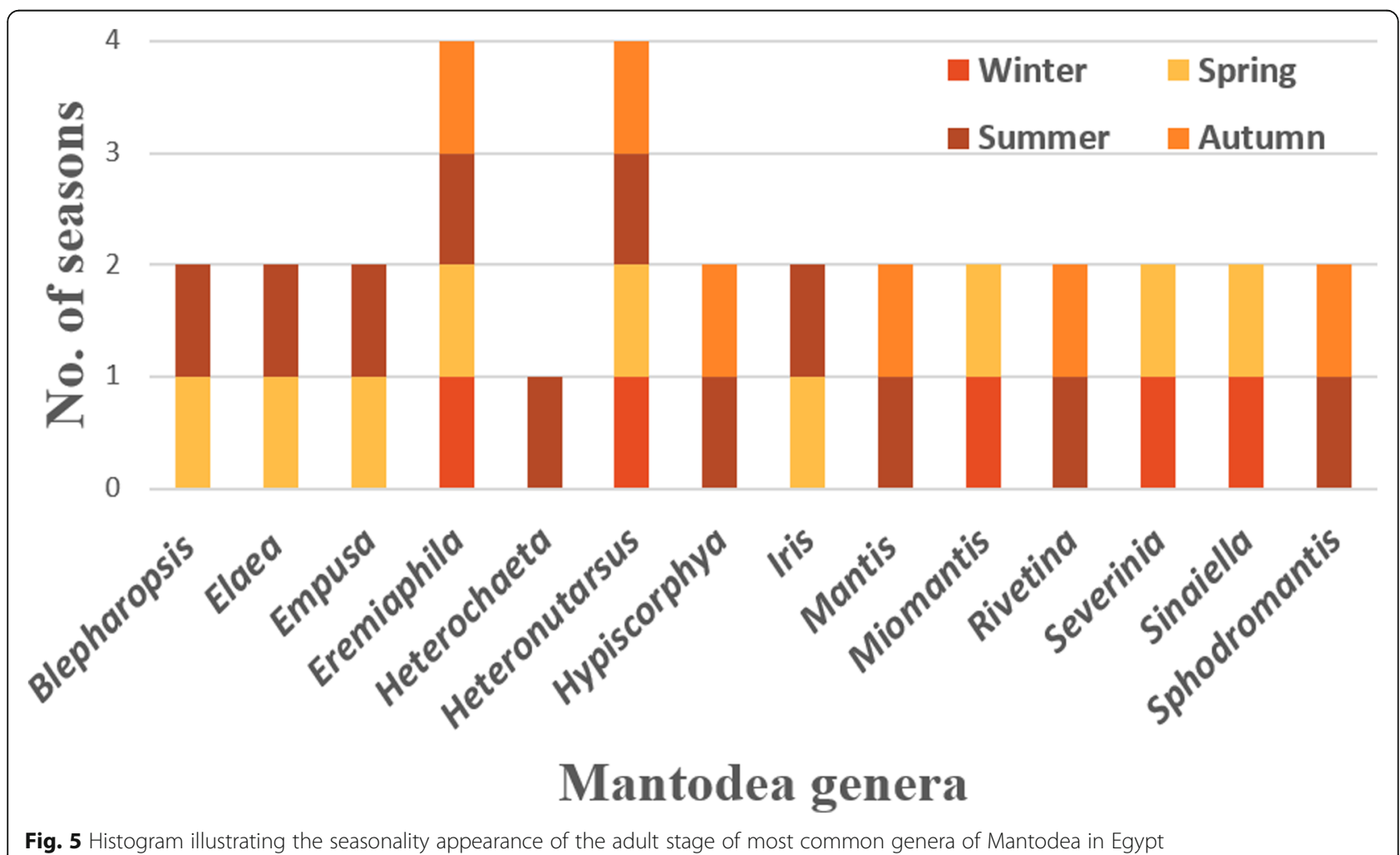

Fig. 5 Histogram illustrating the seasonality appearance of the adult stage of most common genera of Mantodea in Egypt 
their species in unexplored regions such as Gebel Elba. Some interesting species of Mantodea such as Blepharopsis mendica need more attention throughout their whole range including Egypt. Also, species of the interesting genus Eremiaphila need more intensive studies. Our results here form only the beginning step on a better understanding of the Mantodea oasis of the Palaearctic Region (Egypt).

\section{Supplementary Information}

The online version contains supplementary material available at https://doi. org/10.1186/s41938-020-00336-8

Additional file 1. Mantodea records of Egypt. The sheet contains 428 records of Mantodea with their coordinates and the source of each record.

\section{Abbreviations}

Maxent: Maximum entropy; GIS: Geographical Information System; UPGMA: Unweighted pair-group mean arithmetic method; PAST: Paleontological statistics; AUC: Area under the curve; ROC: Receiver operating characteristics; TSS: True skill statistics; ENM: Environmental niche model

\section{Acknowledgements}

The work forms a part of MSc. of the first author concerning the ecology of Mantodea of Egypt and the Middle East using GIS. The authors gratefully thank all the persons who helped in the fieldwork. Also, they appreciate the efforts and help that cautratores of each museum (mentioned in the manuscript) gave to our study.

\section{Authors' contributions}

$\mathrm{MO}, \mathrm{MN}$, and SA contributed to the conceptualization, experimentation, and original draft writing. $\mathrm{MO}$ and MN contributed to the fieldwork. SG and RA contributed to the statistical analysis, manuscript editing, and reviewing. All authors contributed to and accepted the manuscript in its final version.

\section{Funding}

No funding received.

\section{Availability of data and materials}

All used data are included in the manuscript and in the supporting supplementary file.

\section{Ethics approval and consent to participate}

Not applicable.

\section{Consent for publication}

Not applicable.

\section{Competing interests}

The authors declare that they have no competing interests.

\section{Received: 3 July 2020 Accepted: 30 October 2020}

Published online: 16 November 2020

\section{References}

Abutaleb K, Yones MS, El-Shirbeny M, Ma'mon SA, AlAshal S (2019) Modelling and monitoring house fly $M$. domestica using remote sensing data and geographic information system. Egypt J Remote Sens Space Sci. https://doi org/10.1016/j.ejrs.2019.03.001

Adhikari D, Barik S, Upadhaya K (2012) Habitat distribution modelling for reintroduction of llex khasiana Purk., a critically endangered tree species of northeastern India. Ecol Eng 40:37-43

Adly E, Nasser M, Soliman D, Gustafsson DR, Shehata M (2019) New records of chewing lice (Phthiraptera: Amblycera, Ischnocera) from Egyptian pigeons and doves (Columbiformes), with description of one new species. Acta Trop 190:22-27

Anderson R, Dudik M, Ferrier S, Guisan A, Hijmans R, Huettman F, Leathwick J, Lehmann A, Li J, Lohmann L (2006) Novel methods improve prediction of species' distributions from occurrence data. Ecography 29:129-151

Battiston R, Picciau L, Fontana P, Marshall J (2010) Mantids of the EuroMediterranean area. World Biodiversity Association, Verona

Brown JH, Lomolino MV (1998) Biogeography. USA, 2nd edn. Sinauer Associates, Sunderland

Dice LR (1945) Measures of the amount of ecologic association between species. Ecology 26:297-302

Ehrmann R (1996) Die Mantodea fauna von Ägypten. Entomol Z a. M 106:410-424

Ehrmann R (2001) Gottesanbeterinnen (Mantodea) - Eine Übersicht. Teil 1. Stammesgeschichte, Systematik, Körperbau, Fortpflanzung. Reptilia 28:26-32

Ehrmann R (2002) Mantodea: Gottesbeterinnen der Welt. Natur und Tier-Verlag, Münster, p 519

El-Hawagry M, Gilbert F (2014) Zoogeographical affinities and faunal relationships of bee flies (Diptera: Bombyliidae) in Egypt. Zool Middle East 60:50-56

El-Hawagry MS (2002) Distribution, activity periods, and an annotated list of bee flies (Diptera: Bombyliidae) from Egypt. Efflatounia 2:21-40

Elith J, Leathwick JR (2009) Species distribution models: ecological explanation and prediction across space and time. Annu Rev Ecol Evol Syst 40:677-697

El-Moursy A, El-Hawagry M, Abdel-Dayem M, Fadl H (2001) Insect diversity in zaranik protectorate, Northern Sinai, Egypt. Egypt J Nat Hist 3:62-80

Enan R, GadAllah S, Okely M, Nasser M (2017) Historical review of Mantodea occurrence in Egypt with notes about Eremiaphila spp. in the Middle East and North Africa. Eur J Zool Res 5(2):25-33

Ganeshaiah K, Barve N, Nath N, Chandrashekara K, Swamy M, Uma Shaanker R (2003) Predicting the potential geographical distribution of the sugarcane woolly aphid using GARP and DIVA-GIS. Curr Sci 85:1526-1528

Giglio-Tos E (1921) Mantodea. Subfamilie: Eremiaphilinae. Genera Insectorum, fascicule

Greyvenstein B, Du Plessis H, Moulin N, Van den Berg J (2020) Distribution of Galepsus spp. in Southern Africa and life history of Galepsus lenticularis (Mantodea: Tarachodidae). Insects 11(2):119

Hammer $\varnothing$, Harper DAT, Ryan PD (2001) Past: paleontological statistics software package for education and data analysis. http://www.palaeo-electronica.org/2 001 1/past/issue1_01.htm

Hernandez PA, Franke I, Herzog SK, Pacheco V, Paniagua L, Quintana HL, Vargas J (2008) Predicting species distributions in poorly-studied landscapes. Biodivers Conserv 17:1353-1366

Hirzel AH, Hausser J, Chessel D, Perrin N (2002) Ecological-niche factor analysis: how to compute habitat-suitability maps without absence data? Ecology 83: 2027-2036

Hoath R (1993) Natural selection: a year of Egypt's wild life. American University Press, Cairo, p 4

Hogue CL, Powell JA (1980) California insects. University of California Press, Berkeley

Hosni EM, Nasser MG, Al-Ashaal SA, Rady MH, Kenawy MA (2020) Modeling current and future global distribution of Chrysomya bezziana under changing climate. Sci Rep 10(1):1-10

Hurd LE, Eisenberg RM, Moran MD, Rooney TP, Gangloff WJ, Case VM (1995) Time, temperature, and food as determinants of population persistence in the temperate mantid Tenodera sinensis (Mantodea: Mantidae). Environ Entomol 24:348-353

Keerthi MC, Sravika A, Mahesha HS, Gupta A, Bhargavi HA, Ahmed S (2020) Performance of the native predatory bug, Eocanthecona furcellata (Wolff) (Hemiptera: Pentatomidae), on the fall armyworm, Spodoptera frugiperda (JE Smith) (Lepidoptera: Noctuidae), and its limitation under field condition. Egypt J Biol Pest Control 30(1):1-4

Ladle R, Whittaker RJ (2011) Conservation biogeography. Wiley, Oxford Levine RS, Peterson AT, Benedict MQ (2004) Geographic and ecologic distributions of the Anopheles gambiae complex predicted using a genetic algorithm. Am J Trop Med Hyg 70:105-109

Ma'moun S, Yones MA, Mahmoud DM, Al-Ashaal SA, Salama MS, Rady MH (2017) Remote sensing and geographic information system in mapping the distribution of Musca domestica in Al-Fayoum Governorate Egypt. Int J Curr Res 9(01):45189-45195

Marshall JA (1975) A catalogue of the primary types of Mantodea (Dictyoptera) in the British Museum (Natural History). Bull Br Mus Nat Hist Entomol 31(8):309329 
Mohammad SK, Gad Alla S, El-Hamouly H, Ehrmann R, El-Den Nasser M (2011) Mantodea of Egypt. Zootaxa 3044:1-27

Moulin N (2020) When Citizen Science highlights alien invasive species in France: the case of Indochina mantis, Hierodula patellifera (Insecta, Mantodea, Mantidae). Biodivers Data J 8:e46989

Moulin N, Decaëns T, Annoyer P (2017) Diversity of mantids (Dictyoptera: Mantodea) of Sangha-Mbaere Region, Central African Republic, with some ecological data and DNA barcoding. J Orthoptera Res 26(2):117-141

Nasser M (2010) Taxonomic revision and cuticular hydrocarbon profile of Order Mantodea in Egypt. M.Sc. thesis, Ain Shams University, Cairo

Nasser M, Alahmed A, Ansari M, Adly E, Shobrak M (2019b) An analysis of osprey/ chewing lice interaction, with a new record for Saudi Arabia. Afr Entomol 27(1):178-184

Nasser M, El-Hawagry M, Okely M (2019a) Environmental niche modeling for some species of the genus Anthrax Scopoli (Diptera: Bombyliidae) in Egypt, with special notes on St. Catherine protected area as a suitable habitat. J Insect Conserv 23(5-6):831-841

Nasser MG, Al-Ahmed A, Ansari MJ, Shobrak MY (2015) Chewing lice (Phthiraptera) infesting breeding Suliformes (Aves: Aequornithes) of the Arabian Peninsula. Afr Inver 56(3):709-717

Okely M, Anan R, Gad-Allah S, Samy AM (2020) Mapping the environmental suitability of etiological agent and tick vectors of Crimean-Congo hemorrhagic fever. Acta Trop 203:105319

Otte D, Spearman LA (2005) Mantida species file: catalog of the Mantids of the World. Association of Insect Diversity, Philadelphia, p 489

Pearson RG, Raxworthy CJ, Nakamura M, Townsend Peterson A (2007) Predicting species distributions from small numbers of occurrence records: a test case using cryptic geckos in Madagascar. J Biogeogr 34:102-117

Peterson AT, Papeş M, Eaton M (2007) Transferability and model evaluation in ecological niche modeling: a comparison of GARP and Maxent. Ecography 30:550-560

Peterson AT, Papeş M, Soberón J (2008) Rethinking receiver operating characteristic analysis applications in ecological niche modeling. Ecol Model 213:63-72

Phillips SJ, Anderson RP, Schapire RE (2006) Maximum entropy modeling of species geographic distributions. Ecol Model 190:231-259

Preston-Mafham KG (1990) Grasshoppers and mantids of the world. Blandford Books, London

Prete FR, Hurd LE, Branstrator D, Johnson A (2002) Responses to computergenerated visual stimuli by the male praying mantis, Sphodromantis lineola (Burmeister). Anim Behav 63:503-510

Ranade SP, Mukherjee S, Ghate HV (2004) A note on desert mantis Eremiaphila rotundipennis Kirby (Insecta: Mantodea: Eremiaphilidae) from Rajasthan, India. Zoos' Print J 19:1694-1695

Sawaby RF, El-Hamouly H, Nasser MG (2010) Pilot study of population density and biodiversity index of Mantodea fauna in El-Fayoum governorate. Egypt Acad J Biol Sci 3:19-26

Schwarz CJ, Roy R (2019) The systematics of Mantodea revisited: an updated classification incorporating multiple data sources (Insecta: Dictyoptera). Ann Soc Entomol Fr 55:101-196

Shcherbakov EO, Savitsky VY (2015) New data on the fauna, taxonomy and ecology of praying mantises (Dictyoptera, Mantodea) from Russia. Entomol Rev 95(2):181-199

Sørensen T (1948) A method of establishing groups of equal amplitude in plant sociology based on similarity of species and its application to analyses of the vegetation on Danish commons. Biologiske Skrifter 5:1-34

Swets JA (1988) Measuring the accuracy of diagnostic systems. Science 240 1285-1293

Symondson W, Sunderland K, Greenstone M (2002) Can generalist predators be effective biocontrol agents? Annu Rev Entomol 47:561-594

\section{Publisher's Note}

Springer Nature remains neutral with regard to jurisdictional claims in published maps and institutional affiliations.

\section{Submit your manuscript to a SpringerOpen ${ }^{\circ}$ journal and benefit from:}

- Convenient online submission

- Rigorous peer review

- Open access: articles freely available online

- High visibility within the field

- Retaining the copyright to your article

Submit your next manuscript at $\boldsymbol{\nabla}$ springeropen.com 